\title{
Research on the Screening Mechanism of State- owned Enterprises Managers
}

\author{
Yuqiao Li \\ School of Government Administration \\ Beijing Normal University \\ Beijing, China 100875
}

\begin{abstract}
In research on China state-owned enterprise manager, the most important and core content is the selection mechanism of state-owned enterprise and incentive constraint mechanism. To study the incentive and restraint mechanism of top managers in China state-owned enterprises is inseparable from the selection mechanism. Through the establishment of more general screening model, polyarchy and hierarchy screening model, comparing the different structures of screening model on passing rate and average capability, providing suggestions to state-owned enterprise. This article focus on the screening structure and screening performance concluded that the polyarchy passing rate is better than hierarchy, but hierarchy managers' average capability is higher than the polyarchy. Meanwhile, in the absence of a competitive labor market, hierarchy screening is seen as an internal labor market, more suitable for manager selection.
\end{abstract}

Keywords-state-owned enterprises; selection mechanism; business performance; top manager

\section{INTRODUCTION}

Since the 1980 s, state-owned enterprises has to face up the problem of selection top managers, and makes great effort to find out an effective way to solve this problem for state-owned enterprises. Since 2003, the state-owned assets supervision and administration commission has established, in charge of dispatched and assigned top managers to enterprises. Under the market economy system, enterprise top managers should come from the manager market, however, the current state-owned enterprise managers generally comes from two channels: first, from the labor market; second, it is appointed by the government or internal promotion. State-owned enterprise top managers are mostly appointed by state assets management department or the superior assessment department, most state-owned enterprises managers have official status. On the one hand, they also have some characteristics of managers, but on the other hand, they are not restricted by the market competition. Therefore, the western corporations pay system model is not suitable in such environment, economic incentive or nonexecutive promoted doesn't work.

\section{The Existing Problems IN SELECTION}

The state-owned enterprises managers are appointed by the government with the following characteristics [1]:(1) the method of appointment has a strong political characteristics, and the enterprise managers are mainly appointed by the superior departments (2) the dependence on the government is greater (3) Lack of the evaluation system (4) there is no competitive manager market (5) The state-owned enterprises is in short of professional managers.

\section{THE SCREENING THEORY OF STATE-OWNED ENTERPRISE MANAGERS}

Neoclassical economic theory holds that the labor market is a unified market, which is competitive between the buyer and the seller in the open competition [2]. In this model, the only difference between the wages and conditions of workers is the difference in human capital (skill, experience or formal education) [3].At present, the competitive external labor market has not been established, the selection for stateowned enterprises managers can be regarded as the internal labor market selection, and the managers are mainly from the internal labor market. The essence of the internal labor market is a long-term contract, which constitutes a series of employment system arrangements, such as long-term employment and seniority pay [4]. By internal market selection, enterprise can reduce the information asymmetry and save transaction cost, and effectively reduce the information asymmetry of the ex post moral risks of cost, and it also can reduce the cost of supervision in the process of management effectively. Internal labor market can be regarded as relatively stable with symmetric information of managers, which can reduce training cost and avoid shortterm behavior of opportunism tendency; meanwhile, it also can provide incentive mechanism to managers, so as to improve the overall efficiency of enterprises [5].

\section{DESIGN OF STATE-OWNED ENTERPRISE MANAGERS SCREENING}

Traditionally, most of the state-owned enterprises managers are appointed by the state-owned assets supervision and administration commission, comparing with the market selection the hierarchical appointment range is small, no good for choosing the efficient managers [6]. Therefore, the government has a great moral hazard in the process of selecting state-owned enterprises managers. The managers' performance evaluation and incentive mode are relatively backward, and the process of restricting managers 
is only dependent on administrative means and administrative intervention [7]. Therefore, organization is influenced by its internal structure, and it can also examine the specific relationship between performance and structure from organizational structure aspects. According to the classical theory of statistical inference, these errors correspond to Type- 1 and Type- 2 errors. Type- 1 error means rejects higher capability managers. Type-2 error means accept a lower capability managers. Therefore, it can be assumed that a greater incidence of Type-2 errors in polyarchy and a greater incidence of Type- 1 errors in hierarchy [3].

\section{A. Basic Model}

If there are $\mathbb{N}$ alternative managers, each candidates needs to meet certain conditions, such as, education, work experience, etc., suppose $\mathrm{x}$ is the characteristics of a candidate when meets the conditions, it will be accepted otherwise be rejected. When managers density function is $g$ (x), we assume that managers' capability is the only standard for being accepted (or) rejected.

if $0 \leq \mathrm{p}(\mathrm{x}) \leq 1, \mathrm{p} \in\left[\begin{array}{l}\mathrm{x}) \\ \text { if }, \bar{x}],\end{array}\right.$ makes $\mathrm{p}(\mathrm{x}) \neq 1$, then $\mathrm{p}(\mathrm{x})$ is called a filter. If $\mathrm{p}(\mathrm{x})=p^{\mathbb{0}}(\mathrm{x}) \equiv 1$, called it a non-screening mechanism.

Under the evaluation function, $0 \leq \mathrm{p}(\mathrm{x}) \leq 1$ represent managers selected probability, meet the conditions for ${ }^{X}, \bar{x}$ represents upper limit condition, $\stackrel{x}{=}$ represents the lower limit conditions, ${ }^{x}$ between them. When the $p(x)^{\ddagger 1}$, on behalf of a selection mechanism that won't make all participates are selected, therefore, to be an effective mechanism or filter it must meets certain conditions. $p^{\mathbb{Q}}(\mathrm{x})$ Represents the initial selection, namely there is no selection mechanism. So when $\mathrm{p}(\mathrm{x})=\mathrm{p}^{\mathbb{Q}}(\mathrm{x}) \equiv 1$, means screening mechanism is invalid or no screening mechanism.

Definition 2: if the average value of ${ }^{\mathbf{x}}$ is increased after filtering $\mathrm{p}(\mathrm{x})$, then call $\mathrm{p}(\mathrm{x})$ is an effective screening mechanism.
When candidates meet the certain conditions after screening, the candidates' average ability level are higher than those who never been screening, so we can say that the filter $\mathrm{p}(\mathrm{x})$ is an effective screening mechanism.

Proposition 1: there is $p(x) \in C$, meet $p^{p}(x) \geq 0$, with an $\mathrm{x}$, meets $\mathrm{p}^{\prime}(\mathrm{x})>0$, then $\mathrm{p}(\mathrm{x})$ is an effective screening mechanism. (See appendix for proof) If $\mathrm{p}(\mathrm{x})$ is a continuous function, and satisfy the $\mathrm{p}^{b}(\mathrm{x}) \geq 0$ the selected manager is a monotone increasing, after screening the ability of selected managers' average level are higher than the managers without screening, then $\mathrm{p}(\mathrm{x})$ is an effective screening or filtering mechanisms.

Proposition 2: $p(x)$ is known as an effective screening mechanisms, then called $p^{H}(x)=\mathrm{p}^{2}(\mathrm{x})$ is still an effective filtering mechanisms. (See appendix for proof) $p^{p(x)}$ as a basic filter, if the basic filter is an effective screening mechanism, then the composed filter composite hierarchy $p^{H}(x)$ filter is an effective screening mechanism as well.

Proposition 3: $P(x)$ is known effective filtering mechanisms, and then called $p^{p}(x)=P(x)(2-p(x))$ as well as an effective screening mechanism. (See appendix for proof) $\mathrm{P}(\mathrm{x})$ as a basic filter, if the basic filter is an effective screening mechanism, the polyarchy structure of $\mathbb{p}^{p}(x)$ is still an effective screening mechanism.

Proposition 2, 3 illustrates the same effective screening mechanism, the composite screening mechanisms of polyarchy or hierarchy is still an effective screening mechanism, the selected managers' ability level are higher than the initial distribution of the average ability.

To facilitate analyzing, the model is simplified to assume that there exists a two-dimension market where there are only two enterprises in the market, and the hierarchical screening only contains two levels. Therefore, two dimensions are defined as two filters, filter 1 and filter 2.Then, the process of polyarchy and hierarchy screening is shown in "Table I". In the labor market, two enterprises can select managers, respectively.

TABLE I. POLYARCHY AND HIERARCHY

\begin{tabular}{|l|l|l|l|}
\hline \multicolumn{2}{|c|}{ filter 1 } & accepted & rejected \\
\cline { 3 - 4 } filter 2 & $P(x)$ & $1-P(x)$ \\
\hline accepted & $P(x)$ & $\mathrm{p}^{2}(\mathrm{x})$ & $p(x)(1-P(x))$ \\
\hline rejected & $1-P(x)$ & $p(x)(1-P(x))$ & $p(x)(1-P(x))^{2}$ \\
\hline
\end{tabular}

In particular, the selection of managers in polyarchy is screening by two different enterprises at the same time, which is a kind of combined screening structure. In the hierarchy mode, the selection is composed of two levels, and the selection is a series structure. If the probability of an enterprise to accept the manager is $P(x)$, then the probability for not choosing is $1-P(x)$. So in the hierarchical structure, the probability of a manager is chosen by the lower level is $p$ (x) and the higher level is $\mathrm{p}(\mathrm{x})$, both of them accept that can met through the conditions. Therefore, the probability of hierarchical is $\mathrm{p}^{2}(\mathrm{x})$. Similarly, in the polyarchy, if an enterprise chooses to accept the probability is $P(x)$, the probability of reject is $1-P(x)$. So, polyarchy probability 
for accepting is: $P(x)+P(x)(1-P(x))=$ $p(x)(2-P(x))$. In the screening system, the probability of the manager $\mathrm{x}$ being employed is represented by $P(x)$. The upper corner $\mathrm{H}=\mathrm{P}$, where $\mathrm{H}$ represents the hierarchy and $\mathrm{P}$ represents the polyarchy. The probability of polyarchy and hierarchy selection can be expressed as follows:

$$
\begin{aligned}
& \mathrm{p}^{H} \equiv \mathrm{p}^{2}(\mathrm{x}) ; \mathrm{p}^{\mathrm{p}} \equiv \mathrm{p}(x)(2-P(x)) \\
& \mathrm{n}^{p}-n>0
\end{aligned}
$$

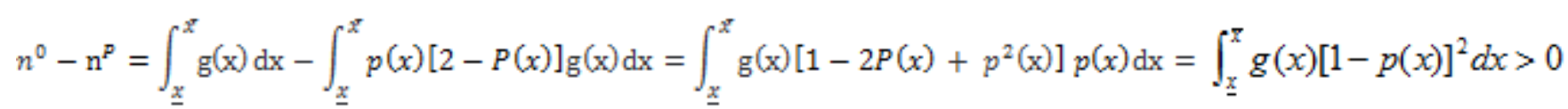$$
\mathrm{n}^{p}-n=\int_{\underline{\underline{x}}}^{g} p(x)[2-P(x)] \mathrm{g}(\mathrm{x}) \mathrm{dx}-\int_{\underline{\underline{x}}}^{\underline{x}} \mathrm{p}(\mathrm{x}) \mathrm{g}(\mathrm{x}) \mathrm{dx}=\int_{\underline{\underline{X}}}^{\pi} p(x)[1-p(x)] g(x) d x>0
$$$$
n-\mathrm{n}^{H}=\int_{\underline{\underline{x}}}^{x^{T}} \mathrm{p}(\mathrm{x}) \mathrm{g}(\mathrm{x}) \mathrm{dx}-\int_{\underline{\underline{x}}}^{x^{x}} \mathrm{p}^{2}(\mathrm{x}) \mathrm{g}(\mathrm{x}) \mathrm{dx}=\int_{\underline{\underline{x}}}^{\mathrm{x}} \mathrm{p}(\mathrm{x})[1-\mathrm{p}(\mathrm{x})] \mathrm{g}(\mathrm{x}) \mathrm{dx}=n^{\mathrm{p}}-\mathrm{n}>0
$$

The explanation for the equation $\int_{x}^{x^{x}} \mathrm{p}(\mathrm{x})[1-\mathrm{p}(\mathrm{x})]_{\mathrm{g}(\mathrm{x}) \mathrm{dx}}$ is as follows:

Definition call $D_{n}(p(x)$

$$
\mathrm{g}(\mathrm{x})=\int_{\underline{x}}^{\pi}\left\{1-p^{n}(x)-[1-p(x)]^{n}\right\} g(x) d x
$$

$$
g(x)
$$

the distribution of for $\mathrm{n}$ dimensional ambiguity of the $\mathrm{p}$

filter

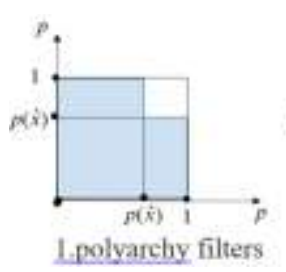

Fig. 1. The pass rate of the three filters.

The "Fig. 2" shows the pass rate of the three filters. The first two filters represent the passing rate in the polyarchy screening. The second is the basic filter, which represents the passing rate of the basic screening; the third, represents the passing rate in the hierarchy structure with two serial filters. The first one, at the bottom of the square, satisfy the two dimensions of polyarchy formed by the filter area, the rectangle area is only meet one dimension pass rate, the section area represented by $\delta(\hat{x})$. It can be seen from the

\section{B. The Comparison of the Pass Rate Under Two Screening Systems}

Proposition 4: the filters with different structures, the average pass rate is, no screening $>$ polyarchy screening $>$ basic screening $>$ hierarchy screening. The expression is:

$$
1=n^{\mathbb{Q}}>\mathrm{n}^{P}>\mathrm{n}>\mathrm{n}^{H}>0
$$

(See appendix for 
managers will vary in terms of performance. It will be discussed below under the two different structures the performance of the output, suppose all managers are only from two kinds of structure, we can make a judgment, which (expect) output is higher.

Proposition 5: the average capability of the manager after screening is higher than that of pre-screening. By comparing the difference between the mean value of the capability before and after screening, shows the capability of the

\section{$\mu^{0}$}

$\mu$

manager. Take as the mean of before screening. Take as $\mu^{H}$

the mean of $\mathrm{x}$ after basic screening;

represents hierarchy $\mu^{P}$

structure with the mean of $\mathrm{x}$, with represents the polyarchy structure with the mean of $\mathrm{x}$.

Pre-screening mean model: ${ }^{\mathrm{p}(\mathrm{x})}=p^{0}(\mathrm{x}) \equiv 1$ 时, $\mu^{0}=\int_{\underline{\underline{x}}}^{\underline{x}} \mathrm{xg}(\mathrm{x}) \mathrm{dx}$

Basic screening model:

$$
\mu=\int_{\underline{\underline{X}}}^{\pi} x p(x) g(x) d x / n=\int_{\underline{\underline{g}}}^{\pi} x \mathrm{G}(x) d x
$$

Hierarchy

screening

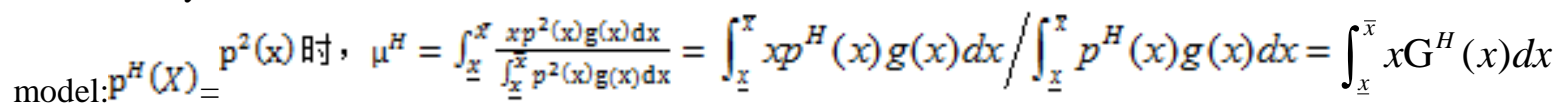

Polyarchy

screening model:

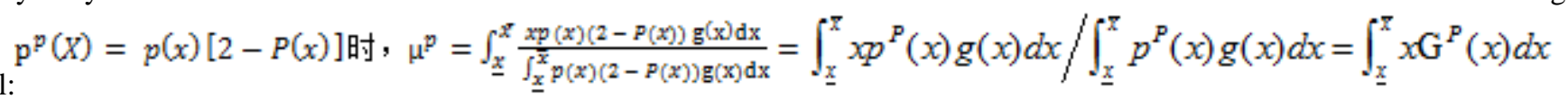

$$
\mu^{s}=E\left[x f^{s}\right]
$$

means managers' average capability is

$$
\Delta \mu=\mu^{P}-\mu^{H}
$$

under the screening system,

means the

differences of managers' average capability between the hierarchical and polyarchy structure.

Comparison between the hierarchical structure and the basic model:

$$
\mu^{p}-\mu=\int_{\underline{x}}^{\underline{x}} \frac{x p(x)(2-P(x)) \mathrm{g}(\mathrm{x}) \mathrm{dx}}{\int_{\underline{x}}^{x} p(x)(2-P(x)) \mathrm{g}(\mathrm{x}) \mathrm{dx}}-\int_{\underline{x}}^{\underline{x}} \frac{\mathrm{xp}(\mathrm{x}) \mathrm{g}(\mathrm{x}) \mathrm{dx}}{\int_{\underline{x}}^{x} \mathrm{p}(\mathrm{x}) \mathrm{g}(\mathrm{x}) \mathrm{dx}}>0
$$

Comparison between basic model and polyarchy structure:

$$
\mu-\mu^{H}=\int_{\underline{x}}^{x} \frac{\mathrm{xp}(\mathrm{x}) \mathrm{g}(\mathrm{x}) \mathrm{dx}}{\int_{\underline{x}}^{x} \mathrm{p}(\mathrm{x}) \mathrm{g}(\mathrm{x}) \mathrm{dx}}-\int_{\underline{x}}^{x} \frac{x p^{2}(\mathrm{x}) \mathrm{g}(\mathrm{x}) \mathrm{dx}}{\int_{\underline{x}}^{x} p^{2}(\mathrm{x}) \mathrm{g}(\mathrm{x}) \mathrm{dx}}>0
$$

Comparison between the hierarchical structure and the polyarchy structure:

$$
\mu^{H}-\mu^{p}=\int_{\underline{x}}^{g} \frac{x p^{2}(\mathrm{x}) \mathrm{g}(\mathrm{x}) \mathrm{dx}}{\int_{\underline{x}}^{x} p^{2}(\mathrm{x}) \mathrm{g}(\mathrm{x}) \mathrm{dx}}-\int_{\underline{x}}^{x} \frac{x p(x)(2-P(x)) \mathrm{g}(\mathrm{x}) \mathrm{dx}}{\int_{\underline{x}}^{\underline{x}} p(x)(2-P(x)) \mathrm{g}(\mathrm{x}) \mathrm{dx}}>0
$$

The results shows the quality of the selection structure, hierarchical screening $>$ basic screening $>$ polyarchy screening > non-screening; the number of selection structure is sorted, non-screening > polyarchy screening > basic screening $>$ hierarchical screening. This is because the comparative advantage in the hierarchical screening is to reject managers with low capability. However, the comparative advantage of polyarchy is to accept managers with high capability. If the initial participants' combined capability is reduced, the advantages of the former will become more and more obvious, and the relative performance of the hierarchy will be improved. However, we need to pay attention to manager's screening probability, it is likely to be influenced by alternative management capability difference. The above expression parameter space can be divided into two areas, one is the market output that is greater than the bureau output; the other one is bureau output that is greater than the market output.

\section{CONCLUSION}

All in all, the market selection can expand the scope of the screening, it is easier to select more outstanding managers, but also more likely to choose lower capability managers, so its defect is easy to leak off higher capability managers. Therefore, the labor market is not perfect, and the managers capability are generally lower, hierarchical 
structure is better than poliarchy. This shows that only in the establishment of a fully competitive labor market, it is more suitable for poliarchy structure. However, in the absence of competitive labor market, it is more suitable for hierarchical selection, because the hierarchical structure is more advantageous to avoid lower managers. And hierarchical selection is more similar to an internal labor market, in this market can solve the information asymmetry problem effectively. Therefore, in view of the state-owned enterprises to select good managers should build a more high-quality competitive labor market, then it is more suitable for poliarchy screening.

\section{REFERENCES}

[1] Li dongsheng. Selection motivation and practical operation of the executives of central enterprises: from the perspective of sasac $[\mathrm{J}]$. Reform, 2009(10):117-122.

[2] Pinfield, Lawrence, (1995). The Operation of Internal Labor Markets. New York. Plenum Press.

[3] Sah R K, Stiglitz J E. The Architecture of Economic Systems: Hierarchies and Polyarchies[J]. Nber Working Papers, 1984, 76(4):716-727.

[4] Yao xianguo, li xu. Labor market segmentation: a literature review [J]. Journal of bohai university (philosophical social science edition), 2005, 27(1):78-83.

[5] Wang lina. Changes in the selection mode of state-owned enterprises in China [J]. Productivity research, 2009(8):134-136.

[6] Yang xiangxing. Economic reflection on the selection and appointment of state-owned enterprise leaders [J]. Management modernization, 2004(5):38-40.

[7] Yang xueyi, wang xinan, research on management changes of stateowned enterprises in China, China social science press, 2012.4.

[8] Dang xiaolong, zhang DE. Analysis on the status quo of succession of large state-owned enterprises in China [J]. Journal of tsinghua university (philosophy and social science edition), 2004, 19(1): 60-63. 